\title{
The role of carbonaceous materials as water channels in membrane sensors together with acrylate polymerized cyclodextrin, for determination of azoxystrobin in canned food
}

Ahmed I. Sheta ( $\nabla$ ahmed.sheta@acu.edu.eg )

Ahram Canadian University

Miriam F. Ayad

Ain Shams University

Amira M. El-Kosasy

Ain Shams University

Shereen M. Tawakkol

Ahram Canadian University

Ahmed S. Fayed

Cairo University

\section{Research Article}

Keywords: quantum dots, azoxystrobin, channels, graphene oxide, nanotubes

Posted Date: February 24th, 2022

DOI: https://doi.org/10.21203/rs.3.rs-1370103/v1

License: (c) (i) This work is licensed under a Creative Commons Attribution 4.0 International License.

Read Full License 


\section{Abstract}

Fungicides of huge organic chemical structures may face some hindrance in passage across membranes of ion-selective electrodes. Thus, the invention of passages within the membrane matrix that selectively engulf these compounds, facilitating their transfer through the membrane.

Carbonaceous materials of nanosized range showed superior ability in increasing ion transfer in comparison with carbon nanotubes. Their combination with acrylates-polymerized-cyclodextrin as ionophore, created two pathways for large organic molecules across the membrane.

Application of both inventions in fabrication of three sensors using carbon nanotubes, graphene quantum dots, and nanographene oxide, enabled trace analysis of azoxystrobin fungicide in ranges (10$12-10^{-5}, 10^{-13}-10^{-4}$ and $\left.10^{-13}-10^{-6} \mathrm{M}\right)$, respectively, with high selectivity.

\section{Introduction}

It was essential to develop highly sensitive and selective analytical methods to analyze traces of azoxystrobin in different matrices without any interference from other pesticides, fertilizers, and matrix effect. Its current maximum residue level (MRL) values range from 0.01 (in some fruits and nuts) to 70 $\mathrm{mg} / \mathrm{kg}$ (in some herbs and edible flowers) [1].

The passage of molecules across the biological membranes needs accessory elements, like ionophores and/or water channels. lonophores shield the charge of one ion, carry it across the membrane and release it. However, channel formers enable the passage of many ions with a high rate [2].

Water channel structures develop highly stable, efficient, and low-energy membranes, by controlling the dynamics of transportation across the membrane. They, either natural or synthetic, can be kept intact and functional through using lipids for the reconstitution of channels and supporting the membrane stability in addition [2].

Herein, carbon nanotubes were used to mimic channels, that are embedded in cell membranes [3]. They can act as artificial water channel that form a transmembrane pore that enhance the membrane permeability for lipophilic drugs [2]. Other carbonaceous materials, like graphene quantum dots and graphene oxide were tested to enhance the permeability of compounds across the membrane.

Azoxystrobin, a white crystalline powder was previously detected by LC MS/MS [4-10], immunoaffinity chromatography (IAC) columns coupled to the high sensitivity of ion mobility spectrometry (IMS) [11], liquid chromatography with dual detection using diode array detection (DAD) and electrospray-ion trap tandem mass spectrometry (ESI-IT-MS/MS) [12], GC with electron capture detection [13], HPLC-UV coupled with GC-MS [14], and voltametrically $[15,16]$.

Polymerization of acrylates and hydroxypropyl $\beta$-cyclodextrin created more rigid cup cavities with many binding sites. Water channel structures develop highly stable, efficient, and low-energy membranes, by 
controlling the dynamics of transportation across the membrane. They, either natural or synthetic, can be kept intact and functional through using lipids for the reconstitution of channels and supporting the membrane stability in addition [2]. Carbonaceous materials, like nano carbon dots, were tested to enhance the permeability of compounds across the membrane.

\section{Materials And Methods}

\subsection{Chemicals and reagents}

All chemicals and solvents are of analytical reagent grade unless mentioned.

Azoxystrobin PESTANAL ${ }^{\circledR}$ (AZX), trifloxystrobin PESTANAL ${ }^{\circledR}$ (TRI), and difenoconazole PESTANAL ${ }^{\circledR}$ (DFC) were purchased from Sigma-Aldrich ${ }^{\circledR}$. Fungicide product, Amistar ${ }^{\circledR}$ Top $(20 \% \mathrm{w} / \mathrm{v}$ AZX $+12.5 \%$ $\mathrm{w} / \mathrm{v}$ difenoconazole) was purchased from Syngenta company agent in Egypt.

Multiwalled carbon nanotubes (MWCNTs) of purity $>95.00 \%$ was purchased from NanoLab (USA). Graphite powder, acetonitrile (HPLC grade) and polyvinyl chloride (PVC) were purchased from SigmaAldrich $\circledast$ (Germany). Dioctyl phthalate (DOP) was purchased from Aldrich (Steinheim, Germany). Tetrahydrofuran (THF) (HPLC grade) was obtained from Fisher ${ }^{\circledR}$ (Germany). Phosphoric acid, potassium permanganate $\left(\mathrm{KMnO}_{4}\right)$, concentrated sulphuric acid $\left(\mathrm{H}_{2} \mathrm{SO}_{4}\right)$, hydrochloric acid $(\mathrm{HCl})$, citric acid $(\mathrm{CA})$ and sodium hydroxide $(\mathrm{NaOH})$ were obtained from Oxford $\circledast$ (India). Boric acid, glacial acetic acid $\left(\mathrm{CH}_{3} \mathrm{COOH}\right)$, potassium chloride $(\mathrm{KCl})$, hydrogen peroxide $\left(\mathrm{H}_{2} \mathrm{O}_{2}\right)$, and ammonium renickate (REN) were purchased from Elgomhouria company, Egypt.

A solution of $10^{-3} \mathrm{M} \mathrm{KCl}$ was prepared by dissolving $7.455 \mathrm{mg}$ in $100 \mathrm{~mL}$ bi-distilled water. BrittonRobinson buffer was prepared by mixing $0.04 \mathrm{M}$ boric acid, $0.04 \mathrm{M}$ phosphoric acid and $0.04 \mathrm{M}$ acetic acid that has been titrated to the desired $\mathrm{pH}$ with $0.2 \mathrm{M} \mathrm{NaOH}$ and $0.2 \mathrm{M} \mathrm{HCl}$ [40].

Silver wire ( $1 \mathrm{~mm}$ diameter, $10 \mathrm{~cm}$ length), battery and copper wires were purchased from the local market.

A stock solution of AZX was prepared by dissolving $40.34 \mathrm{mg} \mathrm{AZX} \mathrm{in} \mathrm{the} \mathrm{least} \mathrm{amount} \mathrm{of} \mathrm{acetonitrile,} \mathrm{and}$ then diluted to $100 \mathrm{~mL}$ with bi-distilled water, to get a solution of $10^{-3} \mathrm{M}$. A serial dilution was made to prepare a calibration set of concentrations $\left(10^{-4}-10^{-13} \mathrm{M}\right)$ using bi-distilled water.

Stock solutions of trifloxystrobin (TRI) and difenoconazole (DFC) were prepared by the same method using $40.84 \mathrm{mg}$ TRI and $40.63 \mathrm{mg}$ DFC, respectively. Further dilutions with bi-distilled water were made to get different concentrations of both interferents (TRI, DFC).

A solution of $10^{-3} \mathrm{M} \mathrm{KCl}$ was prepared by dissolving $7.455 \mathrm{mg}$ in $100 \mathrm{~mL}$ bi-distilled water. BrittonRobinson buffer was prepared by mixing $0.04 \mathrm{M}$ boric acid, $0.04 \mathrm{M}$ phosphoric acid and $0.04 \mathrm{M}$ acetic acid that has been titrated to the desired $\mathrm{pH}$ with $0.2 \mathrm{M} \mathrm{NaOH}$ and $0.2 \mathrm{M} \mathrm{HCl} \mathrm{[17].}$ 
All prepared stock solutions and reagents were kept refrigerated when not in use, at $4^{\circ} \mathrm{C}$.

Silver wire (1 mm diameter, $10 \mathrm{~cm}$ length), battery and copper wires were purchased from the local market.

\subsection{Apparatus}

Graphene quantum dots and graphene oxide nanoparticles were synthesized using a hot plate and centrifuge. Acrylates-polymerized-cyclodextrin powder was synthesized using a thermostatic multiple

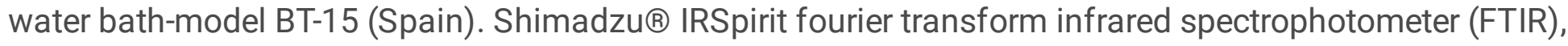
Philips ${ }^{\circledR}$ pw / 830 / 40 X-ray diffraction (XRD) instrument, JEOL JEM-1400 transmission electron microscope (TEM) with carbon microgrid (80 kV) and air drying and Quanta 250 FEG (Field Emission Gun) Scanning Electron Microscope (SEM) (FEI Company, USA) (10.1 mm working distance, with in-lens detector, and excitation voltage $20 \mathrm{kV}$ ) were all used in characterization of synthesized particles and membranes.

A Jenway ${ }^{\circledR} \mathrm{pH}$ meter 3505 UK by Barloworld scientific ltd $\mathrm{pH} / \mathrm{mV} /{ }^{\circ} \mathrm{C}$ meter with Aldrich $\circledast$ glass reference electrode (Ag/AgCl, double junction) Z113107-1EA, House-hold mixer used for homogenization of real samples.

\subsection{Synthesis of acrylates-polymerized-cyclodextrin (APCD)}

Acrylamide and methyl acrylic acid were added to hydroxypropyl $\beta$-cyclodextrin in equimolar ratio (1.33: 1.33: $1.33 \mathrm{mM})$. A crosslinker (10 mM) EGDMA and initiator $(0.15 \mathrm{mM})$ benzoyl peroxide were added. All these components were mixed in porogenic solvent $(5 \mathrm{~mL})$ acetonitrile in a screw-capped glass test tube. After degassing with $\mathrm{N}_{2}$ for five minutes, the tube was sealed and incubated in a thermostatically controlled water bath at $60^{\circ} \mathrm{C}$ for a period of 24 hours [18].

A white polymer was formed inside the tube, that was collected and washed with distilled water to remove unpolymerized parts. Then the polymer was ground in a mortar and left to dry before use. A powdered sample was sent for characterization by X-ray diffraction, FTIR and scanning electron microscope (SEM).

\subsection{Synthesis of graphene oxide (GO)}

Nano graphene oxide was synthesized according to the method mentioned in [19]. Three grams of graphite powder and $18 \mathrm{~g} \mathrm{KMnO}_{4}$ were added gradually and successively to a 9:1 mixture of concentrated $\mathrm{H}_{2} \mathrm{SO} 4 / \mathrm{H}_{3} \mathrm{PO}_{4}(360: 40 \mathrm{~mL})$ with stirring at room temperature in open-mouthed flask. Then, the temperature was raised to $50^{\circ} \mathrm{C}$ with stirring for $18 \mathrm{~h}$. After cooling to room temperature, the mixture was poured onto $400 \mathrm{~mL}$ ice with addition of $30 \mathrm{~mL} \mathrm{H} \mathrm{O}_{2}$ and slightly stirred with glass bar. The mixture was centrifuged (5000 rpm for $5 \mathrm{~min}$ ), and the sediment was collected and washed 7 times with $1 \mathrm{~L} 5 \%$ $\mathrm{HCl}$ solution each time, and further repeatedly with bi-distilled water $(7$ times, $1 \mathrm{~L}$ each time) until pH of 
the supernatant solution approached 7. After washing, the mixture was centrifuged ( $5000 \mathrm{rpm}$ for $5 \mathrm{~min}$ ), and the supernatant was discarded. The paste-like product was collected and dried at $60^{\circ} \mathrm{C}$ under constant vacuum for 2 days. The dried sample was ground, and sent for characterization using FTIR and SEM, to be used in other procedures.

\subsection{Synthesis of graphene quantum dots (GQD)}

Graphene quantum dots were synthesized by a green method that involved direct pyrolysis of citric acid. $2 \mathrm{~g} \mathrm{CA}$ was put into a $5 \mathrm{~mL}$ beaker and heated to $200^{\circ} \mathrm{C}$ using a heating mantle. About 5 min later, the CA was liquated. Subsequently, the color of the liquid was changed from colorless to pale yellow, and then orange in 30 min, implying the formation of GQDs [20]. X-ray diffraction, FTIR and TEM were used for characterization of GQD.

\subsection{Construction of membrane sensors}

Three membranes were fabricated with basic components of $190 \mathrm{mg}$ polyvinyl chloride (PVC), $0.38 \mathrm{~mL}$ plasticizer dioctyl phthalate (DOP), $10 \mathrm{mg}$ ionophore acrylates-polymerized-cyclodextrin (APCD), $10 \mathrm{mg}$ ion-exchanger renickate (REN) and $5 \mathrm{~mL}$ tetrahydrofuran (THF). The water channels forming compound was added in a mount of $10 \mathrm{mg}$ of carbon nanotubes (CN, sensor 1), graphene quantum dots (GQD, sensor 2), and graphene oxide (GO, sensor 3). The whole mixture was mixed in a Petri-dish of $5 \mathrm{~cm}$ in diameter and left covered with filter paper to air-dry overnight. The membrane was cut in circles and pasted on the rubber end of electrode glass body.

A silver wire (1 mm diameter $x 10 \mathrm{~cm}$ length) was covered with silver chloride by dipping in conc $\mathrm{HCl}$, after connecting to the positive pole of a torch battery with a copper wire connected to the negative one. Then it was immersed in internal reference solution $\left(10^{-3} \mathrm{M}, 5 \mathrm{~mL}\right.$ of each $A Z X$ and $\left.\mathrm{KCL}\right)$ to transfer potential to Jenway ${ }^{\circledR}$ potentiometer via a copper wire.

\subsection{Sensor calibration}

After conditioning in $10^{-3} \mathrm{M}$ AZX solutions overnight, sensors were calibrated by immersing separately in about $50 \mathrm{~mL}$ of standard solutions in the concentration range of $\left(10^{-13}-10^{-4} \mathrm{M}\right) \mathrm{AZX}$. Potential difference readings were collected in $\mathrm{mV}$ per decade reduction in concentration following Nernst equation, against Aldrich ${ }^{\circledR} \mathrm{Ag} / \mathrm{AgCl}$ reference electrode. After equilibrium, potential readings were recorded $\pm 1 \mathrm{mV}$. The procedure was repeated in triplicates and the average potentials were calculated. Potential profile was plotted and used in measurement of unknown samples. It should be known that the electrodes were washed with bi-distilled water before each measurement.

\subsection{Effect of $\mathrm{pH}$}

The effect of $\mathrm{pH}$ was studied over the range 1-11 using Britton-Robinson buffer solutions on the response of the constructed electrodes, using $10^{-8}$ and $10^{-9} \mathrm{M}$ AZX.

\subsection{Sensor selectivity}


The constructed sensors were tested toward different interferents TRI and DFC $\left(10^{-7} \mathrm{M}\right)$ to calculate the potentiometric selectivity coefficients, $\mathrm{K}_{\mathrm{A}, \mathrm{B}}{ }^{\text {pot }}$ by using separate solution method (IUPAC. 2000).

$-\log K_{A, B}{ }^{p o t}=E_{A^{-}} E_{B} /\left(2.303 R T / Z_{A} F\right)+\left(1-Z_{A} / Z_{B}\right) \log a_{A}$

where solution $A$ is the solution of $A Z X$ and $B$ is the solution of interferent, $(E)$ is the potential measured, $(Z)$ is the charge of respective ion, $(a)$ is the activity of selected ion, and $\left(2.303 R T / Z_{A} F\right)$ is the slope of investigated sensor calibration curve ( $\mathrm{mV} /$ concentration decade).

\subsection{Determination of azoxystrobin in Marketed Product}

Dilution of $8 \mathrm{~mL}$ Amistar ${ }^{\circledR}$ Top (equivalent to $40.33 \mathrm{mg} \mathrm{AZX)} \mathrm{with} \mathrm{the} \mathrm{least} \mathrm{volume} \mathrm{of} \mathrm{acetonitrile} \mathrm{to}$ dissolve constituents. The volume was completed to $100 \mathrm{~mL}$ with bi-distilled water to get a solution of $10^{-3} \mathrm{M}$. Further dilution was done to get the desired concentration of $10^{-6} \mathrm{M}$. Then, the developed sensors were used in determination of concentration directly without any sample pretreatment.

\subsection{Determination of azoxystrobin in canned marketed product (tomato paste)}

About $10 \mathrm{gm}$ of marketed tomato paste was shaken with $10 \mathrm{~mL}$ acetonitrile then diluted with bi-distilled water to $100 \mathrm{~mL}$. The procedure was applied to detect AZX directly in canned product.

Another sample was prepared by spiking with AZX standard to reach final concentration of $10^{-6} \mathrm{M}$, to be measured by the suggested sensors.

\section{Results And Discussion}

\subsection{Characterization of acrylates polymerized cyclodextrin (APCD)}

Two functional monomers were used in polymerization of a new type of ionophores. This ionophore was synthesized by a simple polymerization reaction, which created a large number of binding sites with increased rigidity of cyclodextrin cup-like cavities [21]. The mechanism of inclusion complex mechanism formation between $\beta$-cyclodextrin and target molecule has been previously investigated and applied to serve as functional monomer [22].

Structural elucidation of ACPD using FTIR showed peaks (forked peak at $2340 \mathrm{~cm}^{-1}$ ) characteristic for acrylate polymers (Fig. 1). Scanning electron microscope image (SEM) confirmed the presence of many binding sites (Fig. 2).

\subsection{Characterization of nano graphene oxide (GO)}


Nano graphene oxide (GO) were found to be highly crystalline as shown in XRD pattern and showed a characteristic fingerprint region in FTIR (Fig. 3, a). Images of TEM showed that GO was in nano size range (Fig. 4, a).

\subsection{Characterization of graphene quantum dots (GQD)}

Graphene quantum dots (GQD) showed some crystallinity in XRD and a characteristic fingerprint region in FTIR (Fig. 3, b). Transmission electron microscope (TEM) images showed that the particles of all synthesized carbonaceous materials were in the nano size range (Fig. 4, b).

\subsection{Membrane sensors}

Scanning electron microscope images for constructed membrane sensors (Fig. 5) showing the alignment of crystalline particles of carbonaceous materials around the cavities of ionophore (APCD). It was noticed that the crystals of GO (Fig. 5, c) were scattered to form larger number of channels than that of CN (Fig. 5, a) or GQD (Fig. 5, b).

\subsection{Sensor calibration}

Regarding ionophore, the incorporation of $\beta$-cyclodextrin in polymerization procedure, increased the sensor sensitivity. This may be due to the great increase in binding sites available for targeted molecule (Table 1). Incorporation of carbonaceous matter enhanced the passage of large fungicide molecule across the membrane. The superior electrical conductivity, high surface area and great stability of graphene oxide nanoparticles (GO) and multi-walled carbon nanotubes (CNTs), explained their role in enhancing the sensors sensitivity [23]. On the other side, graphene quantum dots (GQDs) were more preferred in electrochemical biosensing due to their intrinsic low toxicity, high solubility in many solvents, excellent electronic properties, robust chemical inertness, large specific surface area, abundant edge sites for functionalization, great biocompatibility, low cost, and versatility [24]. All these properties showed wider linearity ranges and explained the little differences between the suggested sensors (Table 1). The sensor response time of less than $1 \mathrm{~min}$, together with the high membrane stability of about 8 weeks were recorded (Fig. 6). 
Table 1

Results obtained over a period of two months for the suggested sensors

\begin{tabular}{|llll|}
\hline Parameters & Sensor 1 & Sensor 2 & Sensor 3 \\
\cline { 2 - 4 } & CN & GQD & GO \\
\hline Slope (mV/decade) ${ }^{[a]}$ & 60.214 & 60.515 & 60.048 \\
\hline Intercept (mV) & 1934.1 & 1308.7 & 1410.7 \\
\hline LOD (M) ${ }^{[b]}$ & $10^{-32}$ & $10^{-21.5}$ & $10^{-23.5}$ \\
\hline Response time (s) & 30 & 30 & 30 \\
\hline Working pH range & $7-10$ & $8-10$ & $1-6,10$ \\
\hline Concentration range (M) & $10^{-12}-10^{-5}$ & $10^{-13}-10^{-4}$ & $10^{-13}-10^{-6}$ \\
\hline Stability (weeks) & & & $100.03 \pm 0.785$ \\
\hline Avg. recovery \% \pm SD [a] & $99.983 \pm 0.603$ & $100.04 \pm 1.256$ & 0.9994 \\
\hline Correlation coefficient & 0.9996 & 0.9989 & \\
\hline $\begin{array}{l}\text { [a] Average of eight determinations for sensors 1 and 3, ten for sensor 2. }{ }^{[b]} \text { Limit of detection was } \\
\text { measured by interception of extrapolated arms of calibration curves. }\end{array}$ \\
\hline
\end{tabular}

\subsection{Effect of $\mathrm{pH}$}

Sensors resistance against different pH changes was observed (Fig. 7) over acidic or basic sides; due to the presence of channels that helped target molecules to pass across the membrane. The poor water solubility of azoxystrobin together with unionization led to minimization of buffering solution to specific pH (Table 1).

\subsection{Sensor selectivity}

Table 2 showed that there was no interference from TRI, or DFC. Conditioning of the membranes together with the strong binding with APCD ionophore, enhanced greatly the sensor selectivity. In addition, the easy passage of AZX through water channels according to concentration gradient on both sides of membrane, made the sensors highly selective.

Table 2. Selectivity coefficients (expressed in Log K) of the proposed sensors in presence of other interferences 


\begin{tabular}{llll} 
Interferents $^{[a]}$ & Sensor 1 & Sensor 2 & Sensor 3 \\
\cline { 2 - 4 } & $\mathrm{CN}$ & GQD & GO \\
\hline Trifloxystrobin (TRI) & -5 & 9 & 4.13 \\
\hline Difenoconazole (DFC) & -5 & 1.2 & 3.64
\end{tabular}

[a] Average of three determinations

\subsection{Determination of $A Z X$ in marketed product}

The suggested sensors could determine the concentration of AZX in marketed product without any interference from additives (Table 3 ).

Table 3. Determination of azoxystrobin in marketed product

\begin{tabular}{llll} 
Marketed product Amistar® Top & \multicolumn{3}{l}{ Average recovery \pm SD [a] } \\
\cline { 2 - 4 } & Sensor 1 & Sensor 2 & Sensor 3 \\
\cline { 2 - 4 } & CN & GQD & GO \\
\hline $10^{-6} \mathrm{M}$ & 93.5 & 97.2 & 95.9 \\
\hline & \pm 1.9 & \pm 1.4 & \pm 0.99
\end{tabular}

[a] Average of three determinations

\subsection{Determination of $A Z X$ in tomato paste}

No detected residues of AZX were detected in the canned product. However, the spiked sample showed good recovery for determination of AZX in this matrix (Table 4).

Table 4

Determination of azoxystrobin in canned tomato paste

\begin{tabular}{|llll|}
\hline Canned tomato paste & \multicolumn{3}{l}{ Average recovery \pm SD [a] } \\
\cline { 2 - 4 } & Sensor 1 & Sensor 2 & Sensor 3 \\
\cline { 2 - 4 } & $\mathrm{CN}$ & GQD & GO \\
\hline $10^{-6} \mathrm{M}$ & 85.6 & 87.2 & 85.9 \\
\cline { 2 - 4 } & \pm 5.7 & \pm 3.4 & \pm 4.99 \\
\hline
\end{tabular}

\section{Conclusion}


Advanced nanomaterials from carbon source play important role in opening water channels that facilitate the permeability of lipophilic large organic molecules across the PVC membranes. Thus, the sensitivity may be increased to detect AZX in its maximum residue levels, and selectivity may be enhanced to determine AZX in presence of combined fungicides or other strobilurins.

The incorporation of $\beta$-cyclodextrin polymerized with acrylates is more premium than $\beta$-cyclodextrin alone.

\section{Declarations}

\section{Conflict of interests}

This work was done without any funding from any association.

No conflicts of interests between authors and any other individual or organization regarding this research.

\section{References}

1. E. Commission, EU Pesticides database. https://ec.europa.eu/food/plant/pesticides/eu-pesticidesdatabase/public/?event=homepage\&language=EN. 2020).

2. R. Sengur-Tasdemir, H.E. Tutuncu, N. Gul-Karaguler, E. Ates-Genceli, I. Koyuncu, Biomimetic Membranes as an Emerging Water Filtration Technology, in: F.N. Kök, A. Arslan Yildiz, F. Inci (Eds.), Biomimetic Lipid Membranes: Fundamentals, Applications, and Commercialization, Springer International Publishing, Cham, 2019, pp. 249-283.

3. P. Nednoor, V.G. Gavalas, N. Chopra, B.J. Hinds, L.G. Bachas, Carbon nanotube based biomimetic membranes: mimicking protein channels regulated by phosphorylation, Journal of Materials Chemistry 17(18) (2007) 1755-1757

4. R. Raina-Fulton, Determination of Neonicotinoid Insecticides and Strobilurin Fungicides in Particle Phase Atmospheric Samples by Liquid Chromatography-Tandem Mass Spectrometry, Journal of Agricultural and Food Chemistry 63(21) (2015) 5152-5162.10.1021/acs.jafc.5b01347

5. W. Yu, X. Luo, X. Qin, M. Huang, J. Li, S. Zeng, K. Zhang, D. Hu, Simultaneous determination and risk assessment of metalaxyl and azoxystrobin in potato by liquid chromatography with tandem mass spectrometry, Environmental Monitoring and Assessment 190(6) (2018) 335.10.1007/s10661-0186717-0

6. D. Hu, X. Xu, T. Cai, W.-Y. Wang, C.-J. Wu, L.-M. Ye, Simultaneous Determination of Isopyrazam and Azoxystrobin in Cucumbers by Liquid Chromatography-Tandem Mass Spectrometry, Journal of Food Protection 80(12) (2017) 2112-2118.10.4315/0362-028x.jpp-17-228

7. L. Shang, Uncertainty evaluation of determination of carbendazim and azoxystrobin residues in grape by ultra performance liquid chromatography-tandem mass spectrometry, Journal of Food Safety and Quality 9(15) (2018) 3948-3953 
8. Y. Chen, X. Qian, Z. Zheng, S. Zhang, Determination of azoxystrobin residue in cucumber by high performance liquid chromatography-tandem mass spectrometry, Journal of Food Safety and Quality 10(10) (2019) 2955-2960

9. X. Zhao, X. Qian, Z. Zheng, Y. Chen, Determination of azoxystrobin and isopyrazam residues and its degradation products in cowpea and soil by high performance liquid chromatography-tandem mass spectrometry, Journal of Food Safety and Quality 9(17) (2018) 4539-4545

10. S. Noegrohati, E. Hernadi, S. Asviastuti, Matrix Effect Evaluation and Method Validation of Azoxystrobin and Difenoconazole Residues in Red Flesh Dragon Fruit (Hylocereus polyrhizus) Matrices Using QuEChERS Sample Preparation Methods Followed by LC-MS/MS Determination, Bulletin of Environmental Contamination and Toxicology 100(6) (2018) 821-826.10.1007/s00128018-2317-5

11. S. Armenta, M. de la Guardia, A. Abad-Fuentes, A. Abad-Somovilla, F.A. Esteve-Turrillas, Off-line coupling of multidimensional immunoaffinity chromatography and ion mobility spectrometry: A promising partnership, Journal of Chromatography A 1426 (2015) 110-

117.http://dx.doi.org/10.1016/j.chroma.2015.11.050

12. P. Viñas, N. Campillo, N. Martínez-Castillo, M. Hernández-Córdoba, Method development and validation for strobilurin fungicides in baby foods by solid-phase microextraction gas chromatography-mass spectrometry, Journal of Chromatography A 1216(1) (2009) 140146.http://dx.doi.org/10.1016/j.chroma.2008.11.036

13. J. Xue, H. Li, F. Liu, W. Jiang, X. Chen, Determination of strobilurin fungicides in cotton seed by combination of acetonitrile extraction and dispersive liquid - liquid microextraction coupled with gas chromatography, Journal of Separation Science 37(7) (2014) 845-852.10.1002/jssc.201301223

14. E.M.H. Abdelraheem, Validation of quantitative method for azoxystrobin residues in green beans and peas, Food chemistry v. 182 (2015) pp. 246-250-2015 v.182.10.1016/j.foodchem.2015.02.106

15. R. Šelešovská, M. Herynková, J. Skopalová, P. Kelíšková-Martinková, L. Janíková, P. Cankař, P. Bednáŕ, J. Chýlková, Oxidation Behavior of Insecticide Azoxystrobin and its Voltammetric Determination Using Boron-doped Diamond Electrode, Electroanalysis 31(2) (2019) 363373.10.1002/elan.201800647

16. R. Šelešovská, M. Herynková, J. Skopalová, P. Kelíšková-Martinková, L. Janíková, J. Chýlková, Reduction behavior of insecticide azoxystrobin and its voltammetric determination using silver solid amalgam electrode, Monatshefte für Chemie - Chemical Monthly 150(3) (2019) 419428.10.1007/s00706-018-2348-y

17. A.M. El-Kosasy, S.M. Tawakkol, M.F. Ayad, A.I. Sheta, A Novel Potentiometric Detection Strategy for the Determination of Amlodipine Besylate Based on Functionalized Particles, Electroanalysis 26(5) (2014) 1031-1038.10.1002/elan.201400025

18. M.F. Abdel-Ghany, L.A. Hussein, N.F. El Azab, Novel potentiometric sensors for the determination of the dinotefuran insecticide residue levels in cucumber and soil samples, Talanta 164 (2017) 518528.https://doi.org/10.1016/j.talanta.2016.12.019 
19. H. Raghubanshi, S.M. Ngobeni, A.O. Osikoya, N.D. Shooto, C.W. Dikio, E.B. Naidoo, E.D. Dikio, R.K. Pandey, R. Prakash, Synthesis of graphene oxide and its application for the adsorption of $\mathrm{Pb}+2$ from aqueous solution, Journal of Industrial and Engineering Chemistry 47 (2017) 169178.https://doi.org/10.1016/j.jiec.2016.11.028

20. Y. Dong, J. Shao, C. Chen, H. Li, R. Wang, Y. Chi, X. Lin, G. Chen, Blue luminescent graphene quantum dots and graphene oxide prepared by tuning the carbonization degree of citric acid, Carbon 50(12) (2012) 4738-4743.https://doi.org/10.1016/j.carbon.2012.06.002

21. M. Rutkowska, J. Płotka-Wasylka, C. Morrison, P.P. Wieczorek, J. Namieśnik, M. Marć, Application of molecularly imprinted polymers in analytical chiral separations and analysis, TrAC Trends in Analytical Chemistry 102 (2018) 91-102.https://doi.org/10.1016/j.trac.2018.01.011

22. G.Z. Kyzas, N.K. Lazaridis, D.N. Bikiaris, Optimization of chitosan and $\beta$-cyclodextrin molecularly imprinted polymer synthesis for dye adsorption, Carbohydrate Polymers 91(1) (2013) 198208.https://doi.org/10.1016/j.carbpol.2012.08.016

23. W. Jin, Y. Fu, W. Cai, In situ growth of CuS decorated graphene oxide-multiwalled carbon nanotubes for ultrasensitive H2O2 detection in alkaline solution, New Journal of Chemistry 43(8) (2019) 33093316.10.1039/C8NJ06134C

24. S. Campuzano, P. Yáñez-Sedeño, J.M. Pingarrón, Carbon Dots and Graphene Quantum Dots in Electrochemical Biosensing, Nanomaterials 9(4) (2019) 634

\section{Figures}



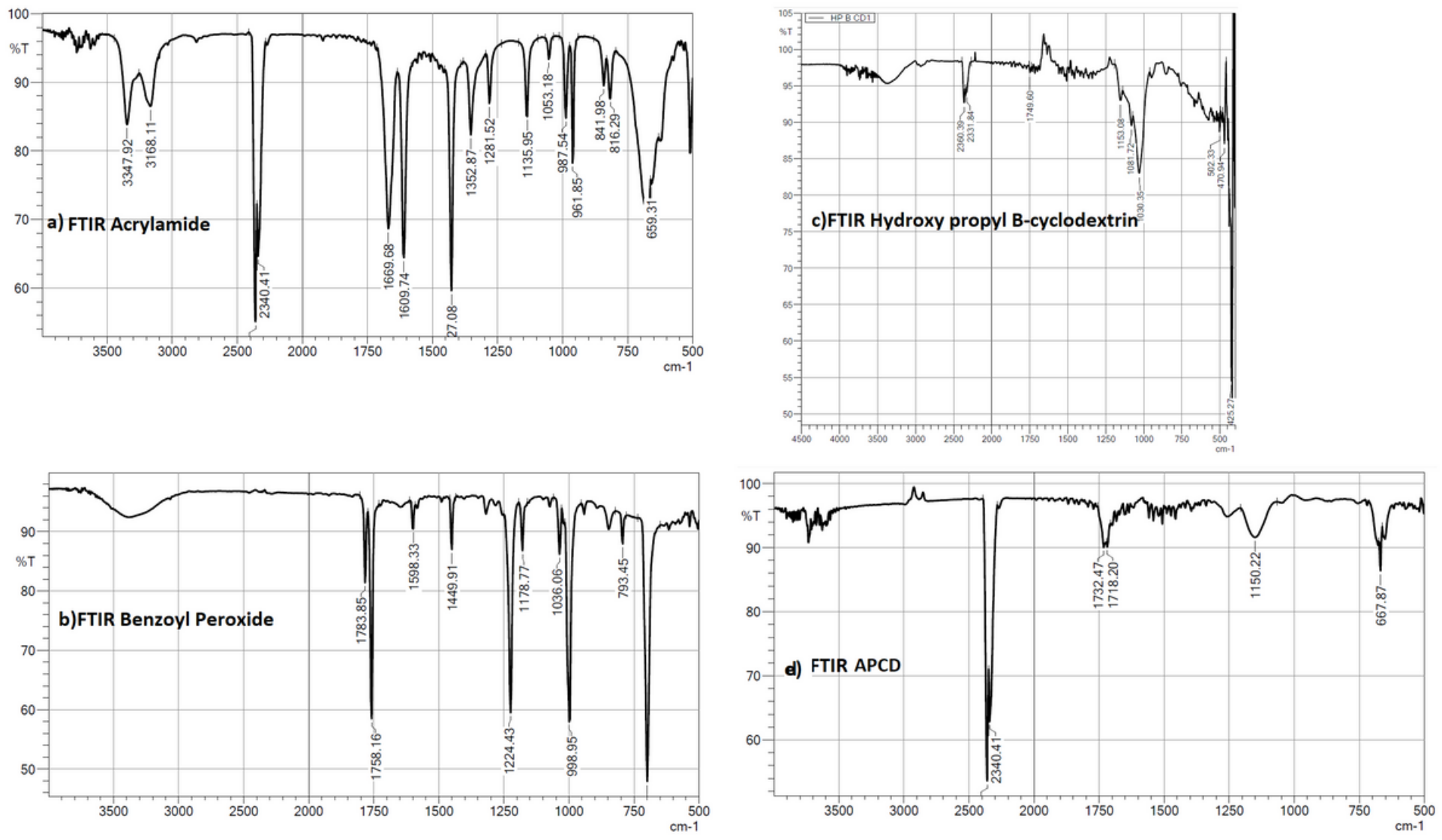

Figure 1

Legend not included with this version.

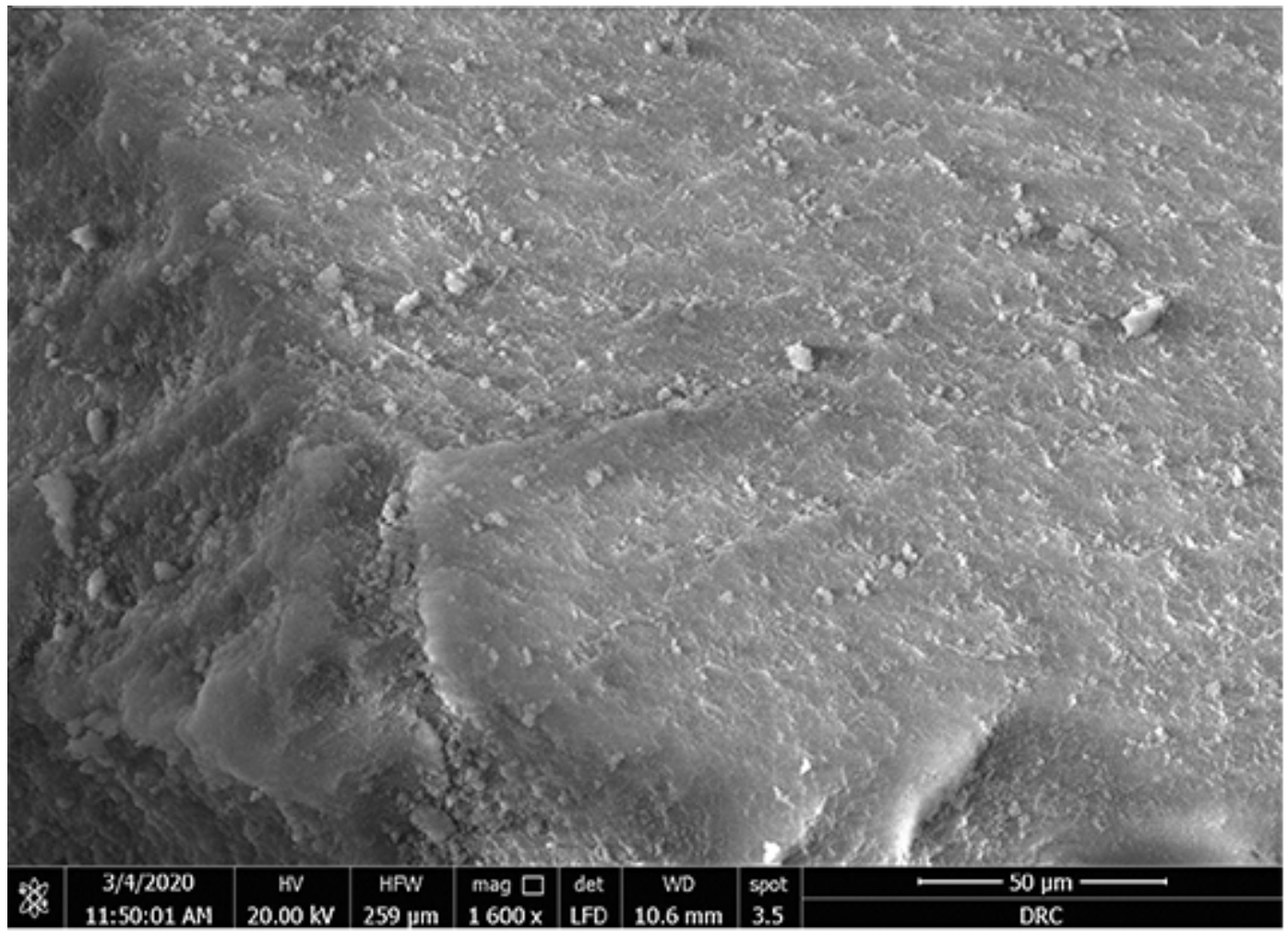


Figure 2

Legend not included with this version
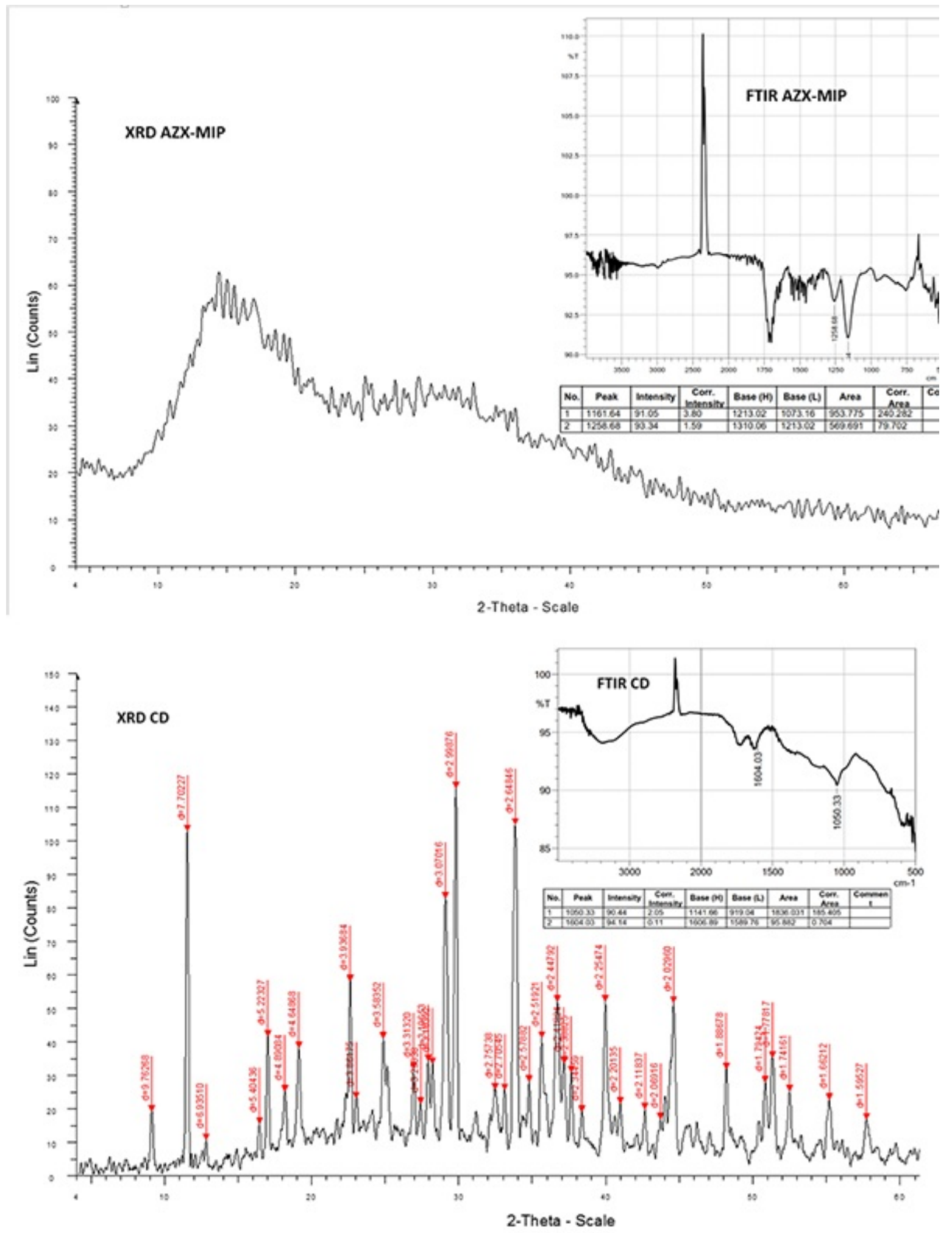

Figure 3

Legend not included with this version 

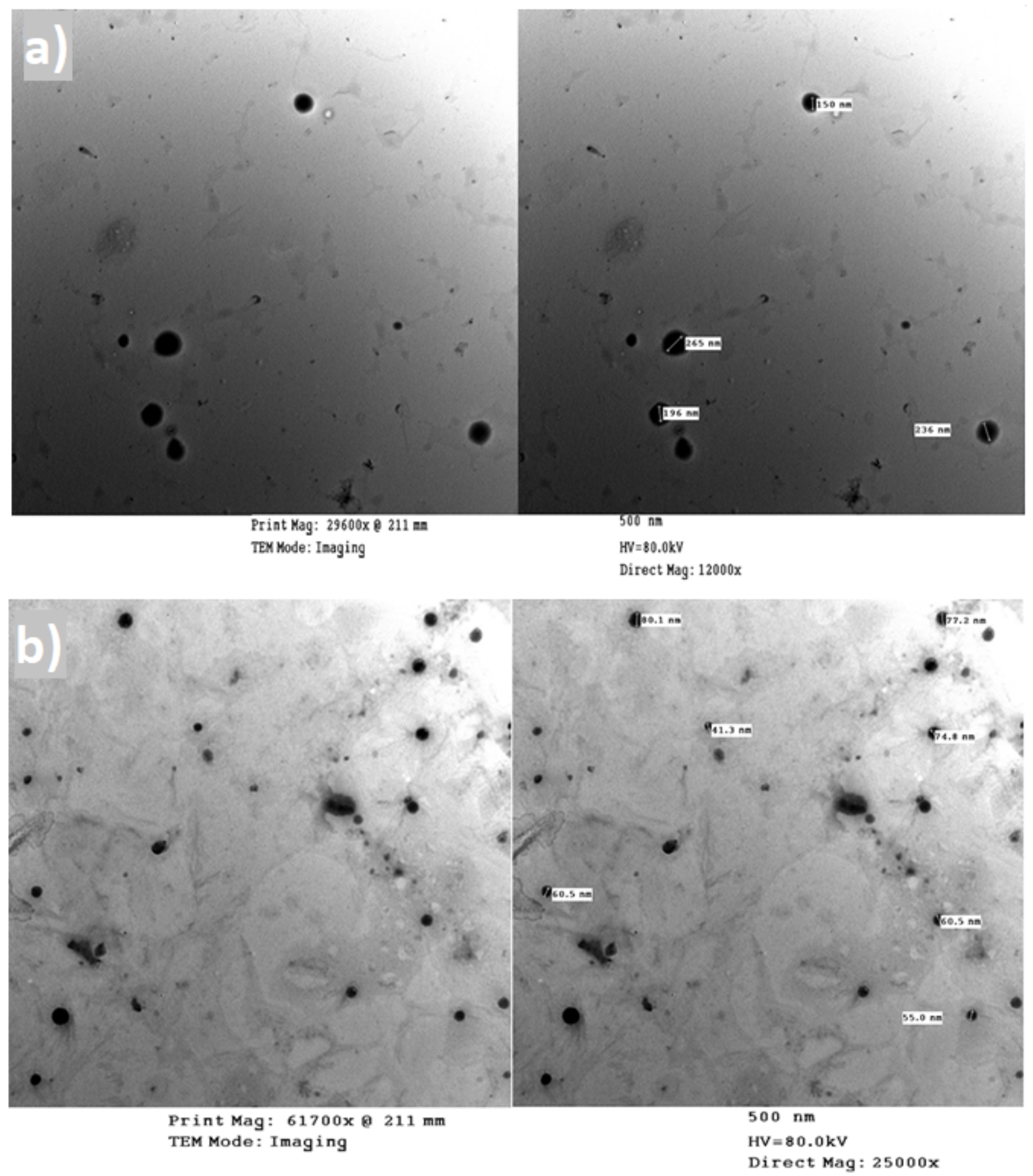

Figure 4

Legend not included with this version 

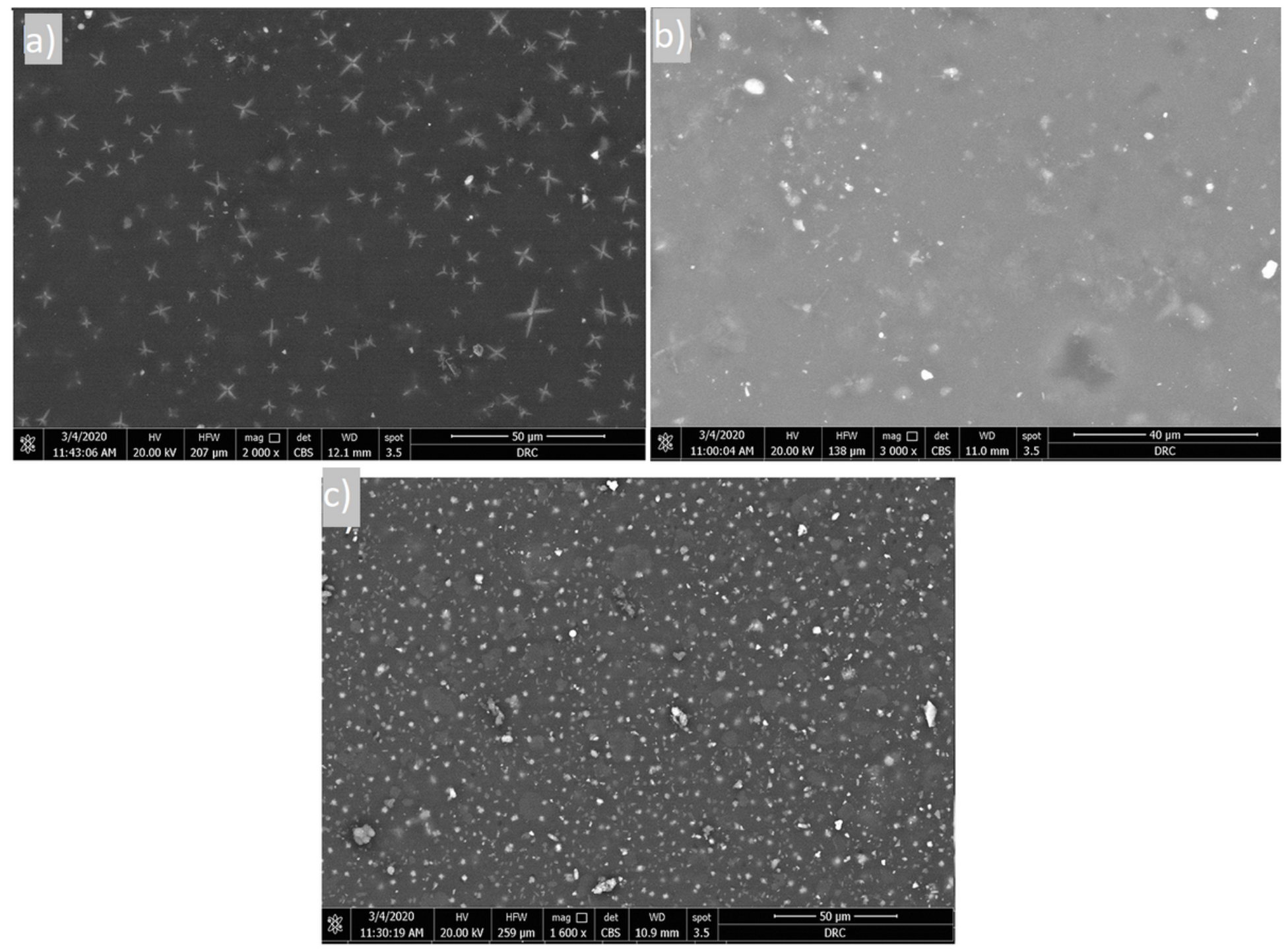

\section{Figure 5}

Legend not included with this version
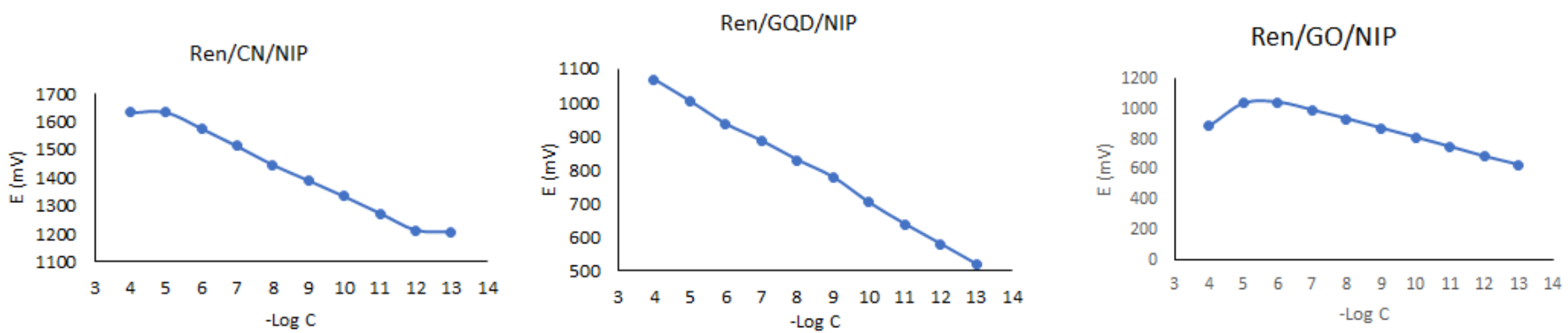

\section{Figure 6}

Legend not included with this version 

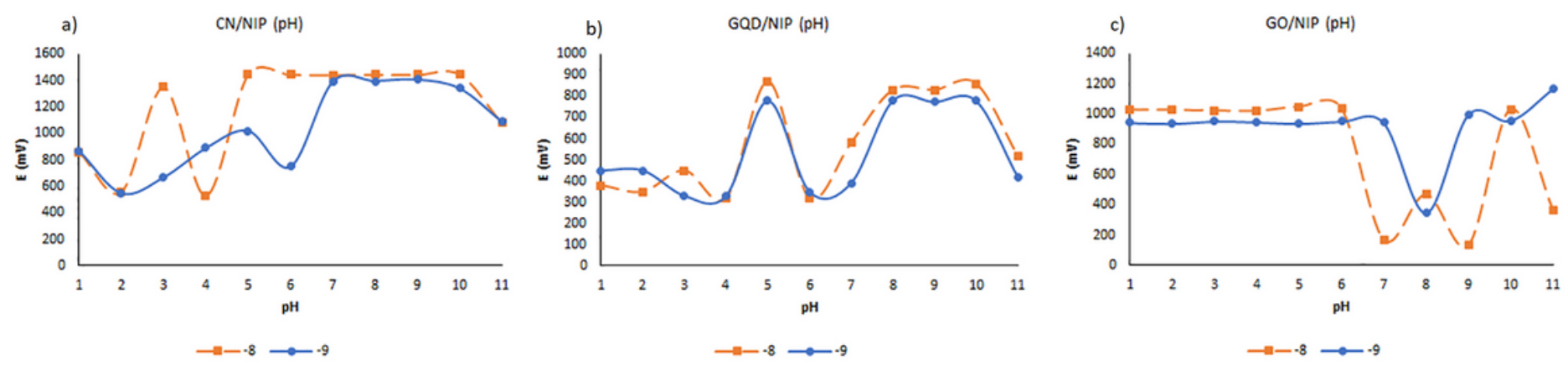

Figure 7

Legend not included with this version 